\title{
Academic Facility Availability and Influence on Students' Academic Performance and Enrollment: Moderating and Mediating Effects of Facility Maintenance
}

\author{
Pearl Abredu \\ School of Management, Jiangsu University, Zhenjiang, 212013, China \\ Yinghua Chen* \\ School of Management, Jiangsu University, Zhenjiang, 212013, China \\ Edwina Naa Amerley Amarteifio* \\ School of Management, Jiangsu University, Zhenjiang, 212013, China
}

\begin{abstract}
Many studies have assessed the influence of a diversity of factors on the academic performance of students but not much can be found on the effects of academic facility availability and functionality on performance and enrollment. In this study, the influence of academic facility availability (AFA) on academic performance (AP) and enrollment of students (E) and the potential mediation and moderating effects of facility maintenance (FM) are studied. A cross-sectional survey, quantitative design was followed and data was assessed using IBM-SPSS (version 25). Multivariate regression analysis was performed after data fitness and collinearity checks were performed. Models were significant for AP and $\mathrm{E}$ with $\mathrm{R}^{2}$ values being 0.8990 and 0.7210 respectively at $\mathrm{P}<0.05$. It was observed that a unit increase in the availability of functional academic facilities in educational institutions in Ghana has the potential to enhance the academic performance of students by about $69.00 \%$, holding all other factors constant. Also, to a significant but lesser degree, the maintenance of existing facilities (FM), when improved by a unit has the potential to also enhance AP by about $41.00 \%$. Further assessment indicated that a unit improvement in AFA in educational institutions had the potential to increase enrollment by about $70.00 \%$, whereas the maintenance of such facilities would only enhance E by $21.00 \%$, ceteris paribus. The PROCESS macro extension was used to test mediation and moderation functions of FM in this study. FM mediated significantly the relationship between AFA and AP $\left(r^{2}=0.7190\right)$ but could not mediate that between AFA and $E\left(r^{2}=0.0893\right)$. A hierarchical multiple regression analysis was conducted to test the moderating effects of FM on the relationship between AFA and AP or E. FM was found to significantly moderated the relationships between AFA and AP/E $(\mathrm{P}<0.05)$.
\end{abstract}

Keywords: Academic facilities; maintenance; mediation; moderation; academic performance; student enrollment. DOI: $10.7176 / \mathrm{JEP} / 10-25-08$

Publication date:September $30^{\text {th }} 2019$

\section{Introduction}

Academic facilities in schools at the primary and secondary levels and at higher learning colleges and universities are often highly associated with the performance of both staff and students, and are most often considered as part of the criteria for grading and ranking of such institutions (Alma et al., 2016; Fareo \& Ojo, 2013; Sidorenko \& Gorbatova, 2015). Academic facilities of educational institutions fall into the category of properties that are strongly linked with the learning and teaching experiences of both faculty and students (Reddy et al., 2016). Examples of such facilities include libraries, laboratories, auditoriums, lecture halls, hostels, sports complexes, shuttle and transport services among others.

Several studies have been carried out concerning the effects of a diversity of factors on the academic performance of students in higher educational institutions. Leung et al. (2019) looked at how environmental greenness influenced academic performance of students. Muñoz-Bullón et al. (2017) also studied the effect of sport participation on performance among others who considered peer effects (Min et al., 2019) and magnet classes (Wu et al., 2019) among others. Not much has been done in the area of direct and indirect influence of academic facilities on the academic success of students; and the availability of such facilities in this context, is defined as the accessibility and usage of existing infrastructure that aid teaching and learning. It is therefore important not to only mention the existence of such facilities, but also their states pertaining to their ability to function at their optimum levels (Hood et al., 2014; Reddy et al., 2016).

The concept of facility maintenance also comes in when the optimum condition and functionality of academic facilities are concerned (Abdallah, 2017; Dickerson \& Ackerman, 2016). This is an area for keen attention which has a direct relationship with both the availability and efficiency of facilities in educational institutions, especially for public owned schools (Flavin, 2019; Pearce, 2017). Functionality, proximity to students, ease of accessibility, regulations of usage, online / or offline modes of access, and carrying capacity, are such terms as may pertain to 
assessing the availability of academic facilities on campuses (Filippi \& Sirombo, 2015; Ibrahim et al., 2016). Notwithstanding the need for academic facilities and their availability in educational institutions, the concept of facility maintenance is key to optimum performance of such facilities (Hasbullah et al., 2011; Izobo-Matins et al., 2018). Beside the provision of such fixed investments in academic facilities and the culture of maintenance ensure sustainable usage, functionality and longevity of facilities and the added benefits that come with them as far as continuing education is concerned (Beder, 1981; Kanters et al., 2014; Turner et al., 2018).

The preference of parent, guardians and students for highly ranked educational institutions and the level of importance attached to such rankings makes it relevant that factors that influence this decision-making process are understood. Among several factors studied, the subject relating to the effect of academic facility availability on the performance of students and on enrollment has not been given much attention. Any factor that has the potential to influence the choice and preference for educational institutions must also be investigated to understand its relationship with academic performance and enrollment levels. This study therefore puts the concept of academic facilities as a criterion for institutional ranking into perspective as far as it influences choice for educational institution. The hypothesis guiding this study were:

$\mathrm{H}_{1}$ : Academic facility availability (AFA) has a positive relationship with academic performance (AP) of students;

$\mathrm{H}_{2}$ : Academic facility availability (AFA) has a positive relationship with student enrollment (E);

$\mathrm{H}_{3}$ : Facility maintenance (FM) mediates the relationship between AFA and AP/E.

$\mathrm{H}_{4}$ : Facility maintenance (FM) moderates the relationship between AFA and AP/E.

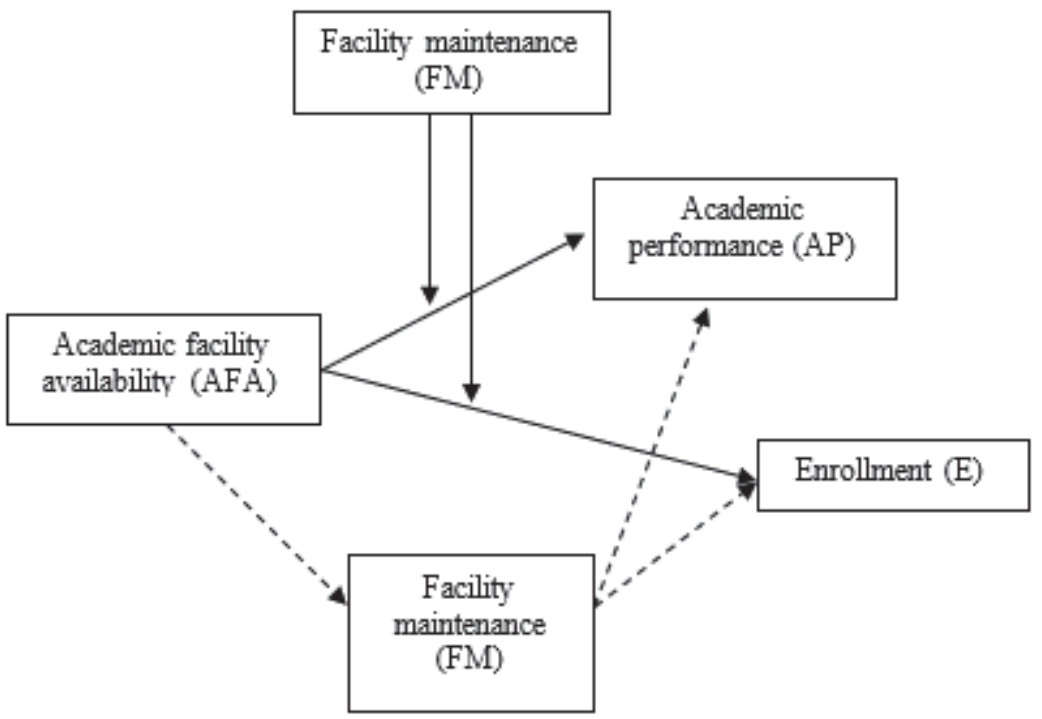

Figure 1: Schematic representation of mediation and moderating roles of facility maintenance on the relationship between academic facility availability and academic performance and enrollment. Dotted lines depict mediation path whereas solid lines depict moderating path. AFA = academic facility availability; AP = academic performance; $\mathrm{FM}$ = facility maintenance; $\mathrm{E}=$ enrollment. 


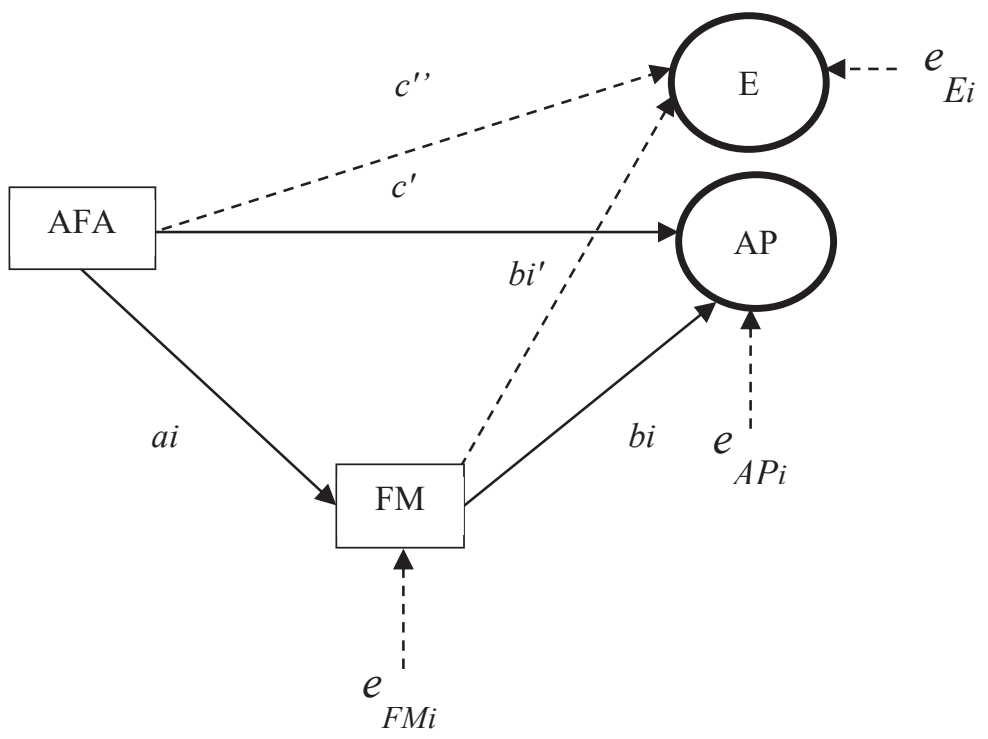

Figure 2: Statistical representation of the mediating effect of FM on the relationship between AFA and AP/E. The direct effect of AFA on $\mathrm{AP}=c^{\prime}$ and the indirect effect of AFA on $\mathrm{AP}=a_{i} b_{i}$. The direct effect of $\mathrm{AFA}$ on $\mathrm{E}=c^{\prime \prime}$ and the indirect effect of AFA on $\mathrm{E}=a_{i} b_{i}$. AFA = academic facility availability; $\mathrm{AP}=$ academic performance; $\mathrm{FM}=$ facility maintenance; $\mathrm{E}=$ enrollment.

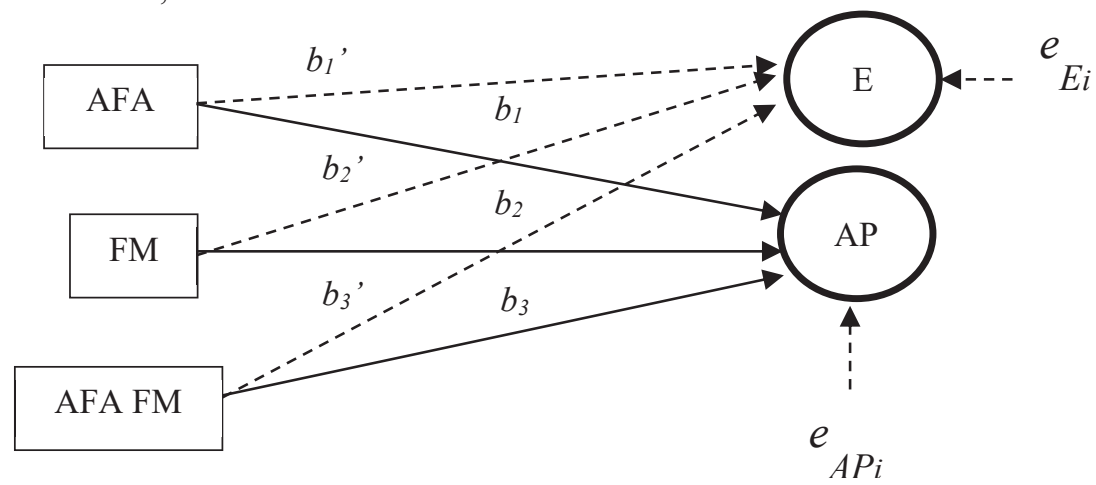

Figure 3: Statistical representation of the moderating effect of FM on the relationship between AFA and AP. The conditional effect of AFA on AP $=b_{1}+b_{3} F M$. The conditional effect of AFA on $E=b_{1},+b_{3}$,FM. AFA $=$ academic facility availability; $\mathrm{AP}=$ academic performance; $\mathrm{FM}=$ facility maintenance; $\mathrm{E}=$ enrollment.

The objective of this study is therefore to investigate the effect of academic facility availability on the academic performance and enrollment of student in tertiary educational institutions in Ghana, considering the potential of facility maintenance as a mediator and moderator (Figure 1). The general concept of the study is represented in a conceptual diagram (Figure 1) and the statistical representations of the mediating and moderating effects of facility maintenance are respectively depicted in Figure 2 and Figure 3.

\section{Methodology}

The study followed a cross-sectional survey and quantitative design. Ten (10) tertiary educational education institutions of higher learning were engaged in this study. They were conveniently sampled from the Ashanti and Greater Accra regions of Ghana based on proximity and ease of access. Thirty (30) respondents were randomly sampled from students from each institution to respond to structured questionnaires on enrollment decision and academic facilities (facility availability, current state, functionality, maintenance, ease of access). Five (5) administrative staff from each institution were also interrogated about available facilities and maintenance, and students' academic performance and enrollment. Secondary data on enrollment and academic performance of students were also gathered from the respective institutions. A total of three-hundred and fifty (350) respondents were involved in this study. Data were organized and coded in SPSS (Version 25) and responses for all variables (AFA, AP, FM, E) were measured using a 5-point Likert scale [(5) strongly Agree, (4) Agree, (3) neither Agree nor Disagree, (2) Disagree, (1) Strongly Disagree]. Mean values of responses and standard deviations were computed for the study variables. Data were assessed using the PROCESS macro extension in SPSS (Version 25) 
ints

according to Hayes' (2018) to establish the relationships between all variables (Figure 1) and the mediating and moderating functions of FM. Data fitness and model predictability were done to validate further statistical assessment and results were presented in Tables and Figures.

\section{Results and discussion}

\subsection{Descriptive statistics and model fitness}

Normality of data was checked (Figure 4 and Figure 5) and fitness for regression assessment was confirmed with correlation matrix and variance inflation factor (VIF) values for multicollinearity checks between variables (Table $1)$.
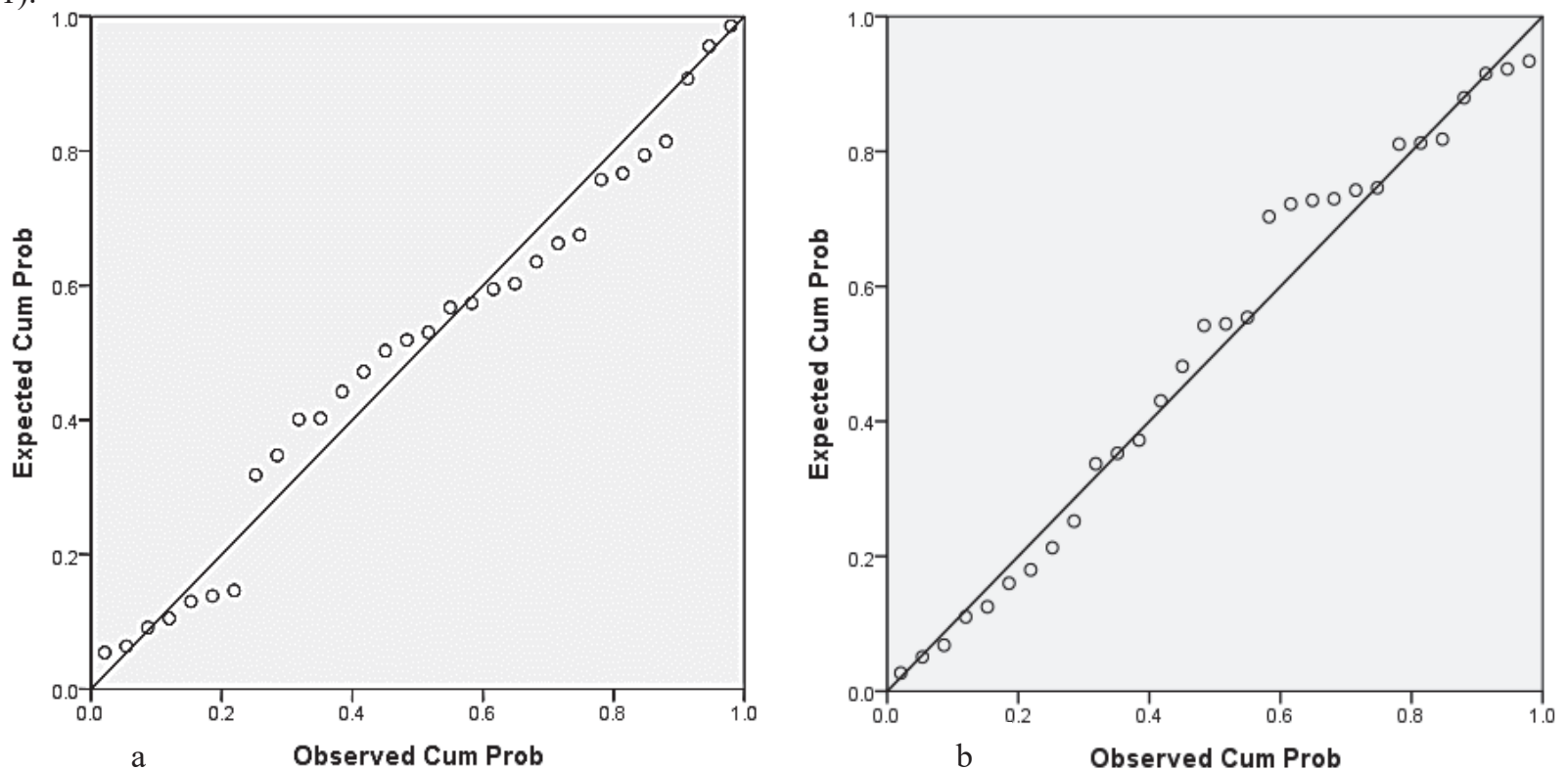

Figure 4: Normality plot of distribution of data. a) academic performance (AP) model; b) Enrollment (E) model

The correlation between independent variables (AFA and FM) was weak at a $99.0 \%$ CI. Moreover, a VIF of 3.0 showed no significant multicollinearity between the independent variables, hence their appropriateness for predicting the variabilities observed in the dependent variable (Table 1). Confirming fitness of data were the strong correlations observed between AFA and AP (0.686) and FM and AP (0.680) (Table 1). Also, AFA and E correlated significantly $(0.405)$ as well as FM and $\mathrm{E}(0.366)$ at a $95.0 \% \mathrm{CI}$. These findings make a good case for the assessment of the relationship between study variables.
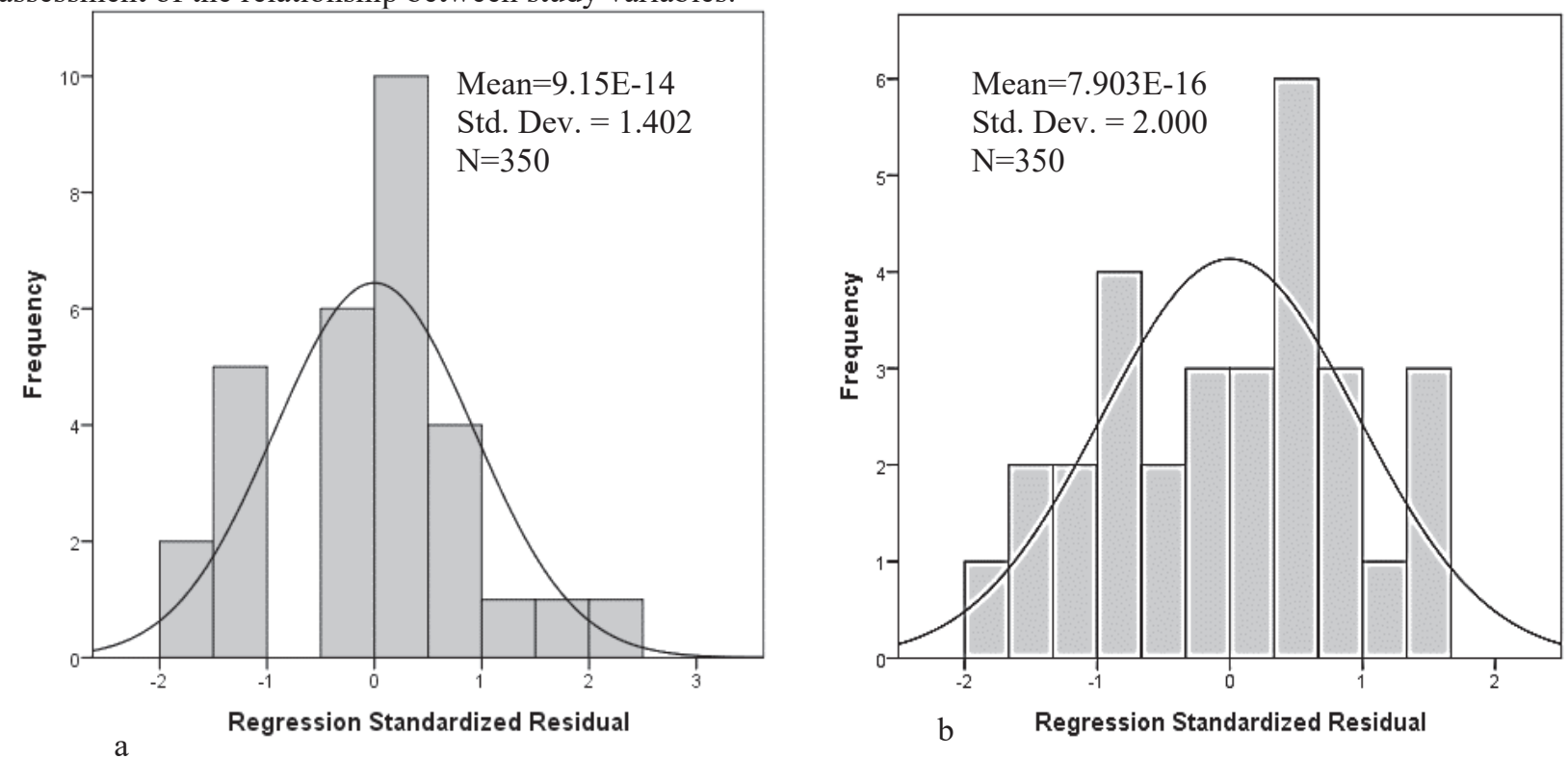

Figure 5: Residual plot for regression models. a) academic performance (AP) model; b) Enrollment (E) model 
Table 1: Correlation matrix for study variables

\begin{tabular}{|c|c|c|c|c|c|}
\hline \multirow{3}{*}{ AFA } & & AFA & \multirow{2}{*}{$\begin{array}{l}\text { FM } \\
.309^{*}\end{array}$} & \multirow{2}{*}{$\begin{array}{l}\text { AP } \\
.686^{* *}\end{array}$} & \multirow{2}{*}{$\begin{array}{l}\mathrm{E} \\
.698^{* *}\end{array}$} \\
\hline & Pearson Correlation & 1 & & & \\
\hline & Sig. (2-tailed) & & .039 & .000 & .833 \\
\hline \multirow{4}{*}{ FM } & $\mathrm{N}$ & 350 & 350 & 350 & 350 \\
\hline & Pearson Correlation & $.309^{*}$ & 1 & $.408^{* *}$ & $.213^{*}$ \\
\hline & Sig. (2-tailed) & .039 & & .000 & .156 \\
\hline & $\mathrm{N}$ & 350 & 350 & 350 & 350 \\
\hline \multirow[t]{3}{*}{ AP } & Pearson Correlation & $.686^{* *}$ & $.408^{* *}$ & 1 & $.691^{* *}$ \\
\hline & Sig. (2-tailed) & .000 & .000 & & .311 \\
\hline & $\mathrm{N}$ & 350 & 350 & 350 & 350 \\
\hline \multirow[t]{3}{*}{$\mathrm{E}$} & Pearson Correlation & $.698^{* *}$ & $.213^{*}$ & $.691^{* *}$ & 1 \\
\hline & Sig. (2-tailed) & .833 & .156 & .311 & \\
\hline & $\mathrm{N}$ & 350 & 350 & 350 & 350 \\
\hline
\end{tabular}

3.2 Multiple regression models and predictability

Regression model summary statistics showed that it was suitable for predicting the establishing the relationship between AFA and AP/E, taking into account the mediating and moderating roles of FM. ANOVA confirmed statistical significance $(\mathrm{P}<0.01)$ with $\mathrm{R}^{2}$ and adjusted $\mathrm{R}^{2}$ values of 0.899 and 0.887 respectively with $\mathrm{AP}$ and 0.721 and 0.698 for $\mathrm{E}$ as dependent variable. This showed that up to about 89.9 and $72.1 \% \%$ of the variabilities observed in AP and $\mathrm{E}$ respectively were predictable by predictor variables. The model equation used in this study to predict the effects of predictor variables on study outcomes is as follows:

$y=\beta_{0}+\beta_{1} x_{1}+\beta_{2} x_{2}+\beta_{3} x_{3}+\beta_{4} x_{4}+\varepsilon \ldots$ (1)

where $\boldsymbol{\beta}_{0}$ is the y-intercept (constant), $\boldsymbol{\beta}_{1} \ldots \ldots \boldsymbol{\beta}_{\boldsymbol{n}}$ are the coefficients of determination for predictor variables, and $\boldsymbol{\varepsilon}$ is the error term. The equation is therefore transformed into equations (2) and (3) for AP and E respectively:

$A P=\beta_{0}+\beta_{1} A F A+\beta_{2} F M \ldots$ (2)

$E=\beta_{0}+\beta_{1} A F A+\beta_{2} F M \ldots$. (3)

Table 2: ANOVA of model terms for relationship between AP, AFA and FM

\begin{tabular}{llrrrrr}
\hline Model & & Sum of Squares & df & Mean Square & F & Sig. \\
\hline 1 & Regression & 142.456 & 2 & 71.228 & 23.839 & $.000^{\mathrm{b}}$ \\
& Residual & 80.671 & 347 & 2.988 & & \\
Total & 223.126 & 349 & & & \\
\multicolumn{2}{l}{ a. Dependent Variable: AP } & & & & & \\
b. Predictors: (Constant), FM, AFA & & & & & \\
\hline
\end{tabular}

From ANOVA of model terms explaining the variability in AP, the model was significant with a $\mathrm{P}$ value less than 0.05 at a $95.0 \%$ CI (Table 2). Model coefficients are presented in Table 3 and show the extent to which each predictor variable influenced the response variable, AP. Predicted with equation (2), the model equation for AP then becomes:

$$
A P=5.925( \pm 1.301)+0.686( \pm 0.201) A F A+0.408( \pm 0.022) F M \ldots(4)
$$

Table 3: Coefficients and VIF values for AP model

\begin{tabular}{|c|c|c|c|c|c|c|c|c|}
\hline \multirow{2}{*}{\multicolumn{2}{|c|}{ Model }} & \multicolumn{2}{|c|}{$\begin{array}{l}\text { Unstandardized } \\
\text { Coefficients }\end{array}$} & \multirow{2}{*}{$\begin{array}{c}\text { Standardized } \\
\text { Coefficients } \\
\text { Beta } \\
\end{array}$} & \multirow[t]{2}{*}{$\mathrm{T}$} & \multirow[t]{2}{*}{ Sig. } & \multicolumn{2}{|c|}{$\begin{array}{l}\text { Collinearity } \\
\text { Statistics }\end{array}$} \\
\hline & & B & Std. Error & & & & Tolerance & VIF \\
\hline \multirow[t]{3}{*}{1} & (Constant) & 5.925 & 1.301 & & 2.760 & .010 & & \\
\hline & AFA & 689 & .201 & .686 & 3.629 & .001 & .857 & 1.167 \\
\hline & FM & .420 & .022 & .408 & 4.063 & .000 & .857 & 1.167 \\
\hline
\end{tabular}

a. Dependent Variable: AP

From prediction model equation (4), it was observed that a unit increase in the availability of functional academic facilities in educational institutions in Ghana has the potential to enhance the academic performance of students by about $69.0 \%$, holding all other factors constant. Also, to a significant but lesser degree, the maintenance of existing facilities (FM), when improved by a unit has the potential to also enhance AP by about $41.0 \%$ considering that all factors are held constant.

Considering the effect of academic facility availability and functionality and their maintenance on the level of enrolment in educational institutions in Ghana, the ANOVA statistics showed that the model was significant $(\mathrm{P}<0.05)$ (Table 4), with calculated coefficients presented in Table 5. 
Table 4: ANOVA of model terms for relationship between E, AFA and FM

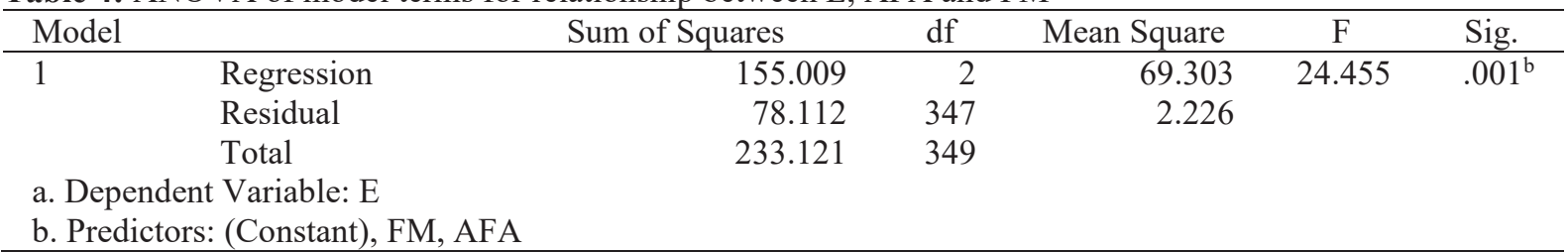

Table 5: Coefficients and VIF values for E model

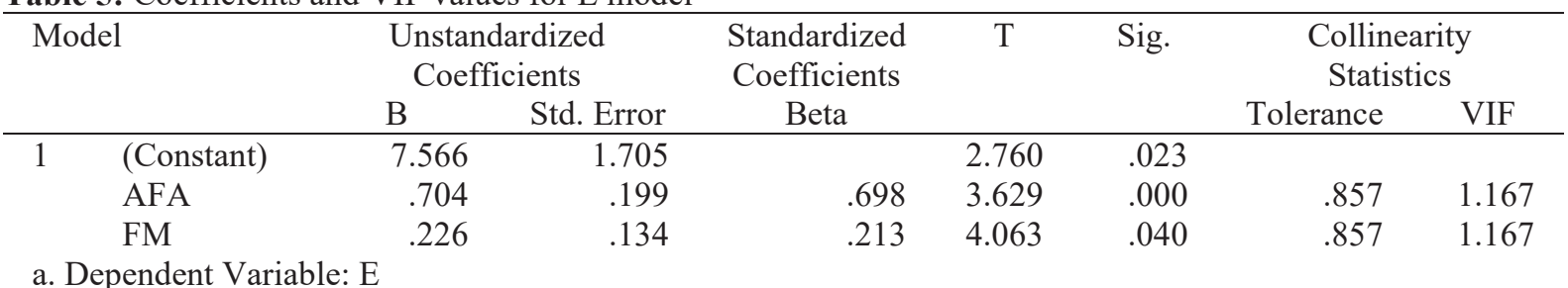

From model prediction coefficients for E, the model equation (2) can be rewritten as:

$E=7.566( \pm 1.705)+0.698( \pm 0.199) A F A+0.213( \pm 0.134) F M$

Results therefore indicated that a unit improvement in AFA in educational institutions had the potential to increase enrollment by about $70.0 \%$, whereas the maintenance of such facilities would only enhance enrollment by $21.0 \%$, ceteris paribus (equation 5).

3.3 Test for mediation of FM on the relationship between AFA and AP/E

The PROCESS macro extension was used to test mediation and moderation functions of FM in this study according to the description by Hayes (2018) in SPSS. Results obtained showed that AFA and AP were significantly related $\left(\mathrm{r}^{2}=0.686\right)$. However, an indirect effect of AFA on AP, through the mediation role of FM showed a higher correlation (0.719) than the direct effect (0.686), with lower and upper CI values being 0.0088 and 0.4013 respectively (Figure 6a). On the other hand, AFA also significantly influenced $\mathrm{E}\left(\mathrm{r}^{2}=0.698\right)$ directly and the indirect relationship through the mediation role of FM revealed that FM did not significantly enhance E among studied educational institutions $\left(\mathrm{r}^{2}=0.0893\right)$ (Figure 6b).
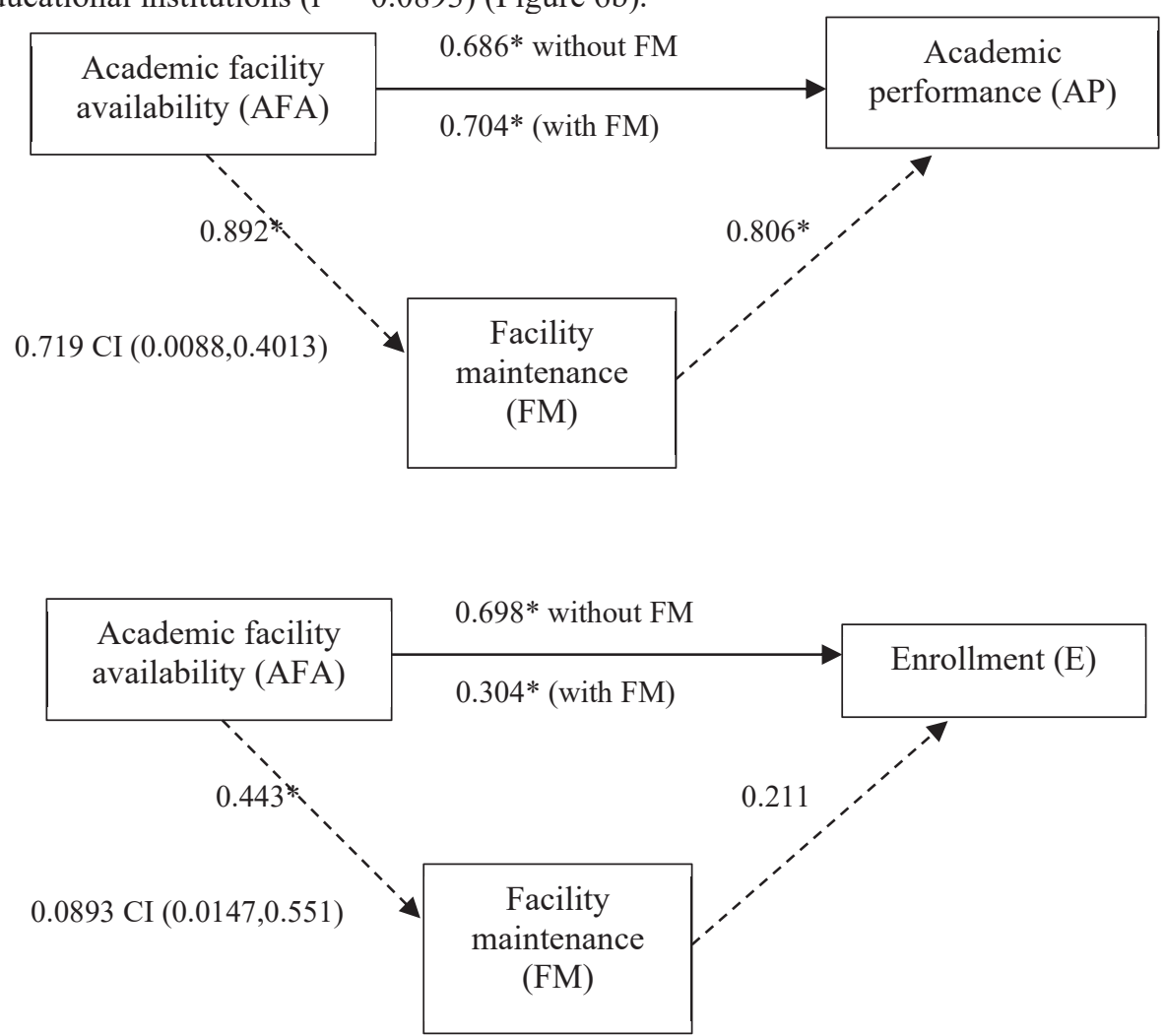

Figure 6: Diagrams showing the mediation effect of FM on the relationship between: a) AFA and AP and b) AFA and $\mathrm{E} . *$ significance. 
3.4 Test for moderation of FM on the relationship between AFA and AP/E

A hierarchical multiple regression analysis was conducted to test the moderating effects of FM on the relationship between AFA and AP or E according to method described by Aiken and West (1991). AFA and FM were included in the first step and they accounted for a significant $(\mathrm{p}<.005)$ amount of variance in AP with $\mathrm{R}^{2}=0.507$. In order to understand the moderating function of FM, an interaction term between AFA and FM was computed and added to the regression model. Results showed that AP was significantly influenced by the interaction from FM, with a change in $\mathrm{R}^{2}=0.173$, change in $\mathrm{F}(2,347)=11.08, \mathrm{P}=0.001$, and $\mathrm{t}=2.37$. For the moderation effect of $\mathrm{FM}$ on $\mathrm{E}$, an interaction term added for AFA and FM also had a significant positive influence on the response observed in $\mathrm{E}$. Change in $\mathrm{R}^{2}=0.095$, change in $\mathrm{F}(2,347)=9.924, \mathrm{P}=0.004$, and $\mathrm{t}=3.13$.

For AP, an interactive plot between AFA and FM (Figure 7) showed a positive relationship between AFA and FM, such that as AFA and FM increased, AP also increased. When AFA scored low, the level of AP was similar for low and average levels of FM, except for high FM which was higher, though insignificantly (Figure 7). Added, high levels of FM showed significant increases in the levels of AP at all levels of AFA. The importance of this findings is that, when the level of AFA is high and in the presence of policies that favour high FM in educational institutions, the highest incidence of AP is observed. This result showed that the moderation effect of FM on the relationship between AFA and AP was significant.

For E, a positive relationship was observed for the influence of AFA and FM on E in the studied educational institutions. On a general basis, improvements in AFA and FM increased E (Figure 8). The effect of the interaction between AFA and FM on E was assessed and a plot developed to show observed trends. In the instance when AFA was low and FM also low, E levels were worst. This meant that, when there are not enough academic facilities available and when those available are given very low maintenance attention, enrollment of students is worst. But in the extreme case scenario when both AFA and FM levels are high, E levels also increase significantly.

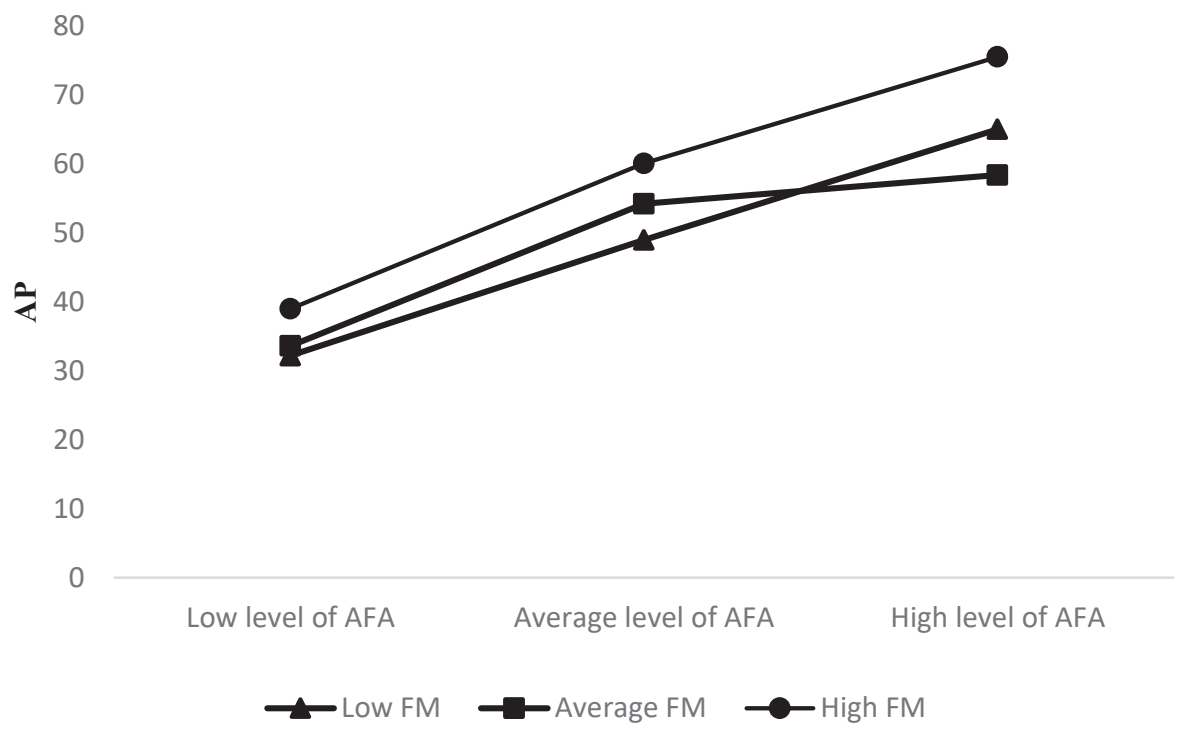

Figure 7: Interactive plot between AFA and FM on AP 


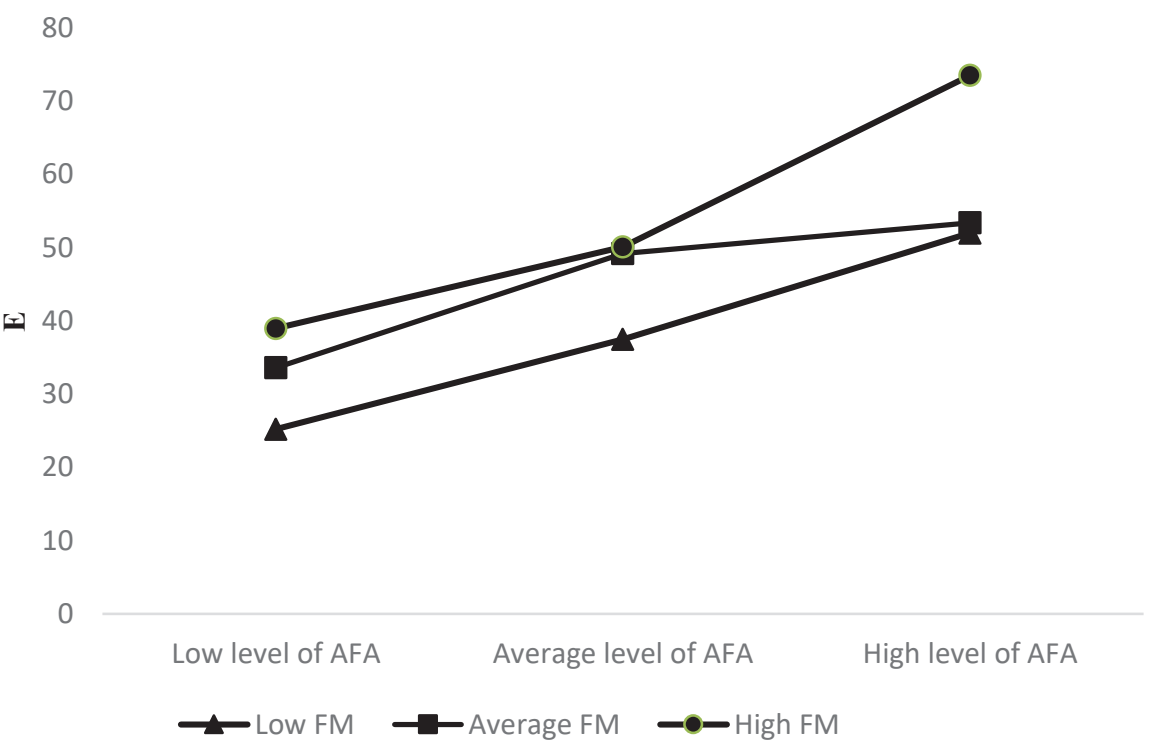

Figure 8: Interactive plot between AFA and FM on E

\section{Conclusion}

This study investigated the effect of academic facility availability (AFA) on academic performance (AP) of students and enrollment (E) in higher educational institutions in Ghana. The study considered the mediating and moderating roles of facility maintenance (FM) on the relationship between AFA and AP/E. Results showed that hypothesis one and two ( $\mathrm{H} 1$ and $\mathrm{H} 2)$ which expected AFA to have a positive effect on AP and E were confirmed and accepted. However, the mediation roles of FM were only confirmed for its effect on the relationship between AFA and AP, and not E, only partially confirming H3. The moderating roles of FM were confirmed for both output variables (AP and $\mathrm{E}$ ) and $\mathrm{H} 4$ confirmed. In essence, educational institutions of higher learning should invest in the provision of academic facilities and ensure their functionality in order to enhance academic performance and student enrollment. Although facility maintenance did not significantly improve enrollment by virtue of its indirect effect on the relationship between AFA and E, its moderating roles were significant and so needs to be considered critically to enhance both AP and E.

\section{References}

1. Abdallah, T. (2017). Chapter 2 - Infrastructure, Facilities and Vehicles. Sustainable Mass Transit- Challenges and Opportunities in Urban Public Transportation, pp. 15-29. https://doi.org/10.1016/B978-0-12-811299$1.00002-2$

2. Alma, B., Coşkun, E., Övendireli, E. (2016). University Ranking Systems and Proposal of a Theoretical Framework for Ranking of Turkish Universities: A Case of Management Departments. Procedia - Social and Behavioral Sciences, 235, 128-138. https://doi.org/10.1016/j.sbspro.2016.11.008.

3. Beder, H. (1981). Strengthening public school support for continuing education. New Directions for Adult and Continuing Education, 1981(9), 65-71. https://doi.org/10.1002/ace.36719810910.

4. Dickerson, D.E., \& Ackerman, P.J. (2016). Risk-based Maintenance Management of U.S. Public School Facilities. Procedia Engineering, 145, 685-692. https://doi.org/10.1016/j.proeng.2016.04.069.

5. Fareo, D.O., \& Ojo, O.O. (2013). Impact of facilities on academic performance of students with special needs in mainstreamed public schools in Southwestern Nigeria. Journal of Research in Special Educational Needs, 13(2), 159-167. https://doi.org/10.1111/j.1471-3802.2011.01228.x.

6. Filippi, M., \& Sirombo, E. (2015). Green Rating of Existing School Facilities. Energy Procedia, 78, 31563161. https://doi.org/10.1016/j.egypro.2015.11.773.

7. Flavin, P. (2019). State government public goods spending and citizens' quality of life. Social Science Research, 78, 28-40. https://doi.org/10.1016/j.ssresearch.2018.11.004.

8. Hasbullah, A., Yusoff, W.Z.W., Ismail, M., \& Vitasari, P. (2011). A framework study of school facilities performance in public primary school of Batubara district in Indonesia. Procedia - Social and Behavioral Sciences, 15, 3708-3712. https://doi.org/10.1016/j.sbspro.2011.04.360.

9. Hood, N.E., Colabianchi, N., Terry-McElrath,E.M., O'Malley, P.M., \& Johnston, L.D. (2014). Physical Activity Breaks and Facilities in US Secondary Schools. Journal of School Health, 84(11), 697-705. https://doi.org/10.1111/josh.12206.

10. Ibrahim, N.M., Osman, M.M., Bachok, S., \& Mohamed, M.Z. (2016). Assessment on the Condition of School 
Facilities: Case Study of the Selected Public Schools in Gombak District. Procedia - Social and Behavioral Sciences, 222, 228-234. https://doi.org/10.1016/j.sbspro.2016.05.151.

11. Izobo-Matins, O., Olotuah, A., Adeyemi, E., Ayo-Vaughan, K., \& Odetunmibi, O.A. (2018). Survey dataset of building user-perceptions on the condition of public secondary school buildings in Ogun State Nigeria. Data in Brief, 19, 2224-2234. https://doi.org/10.1016/j.dib.2018.06.108.

12. Kanters, M.A., Bocarro, J.N., Filardo, M., Edwards, M.B., McKenzie, T.L., \& Floyd, M.F. (2014). Shared Use of School Facilities with Community Organizations and Afterschool Physical Activity Program Participation: A Cost-Benefit Assessment. Journal of School Health, 84(5), 302-309. https://doi.org/10.1111/josh.12148.

13. Leung, W.T.V., Tam, T.Y.T., Pan, W.C., Wu, C.D., \& Spengler, J.D. (2019). How is environmental greenness related to students' academic performance in English and Mathematics? Landscape and Urban Planning, 181, 118-124. https://doi.org/10.1016/j.landurbplan.2018.09.021.

14. Min, S., Yuan, Z., Wang, X., \& Hou, L. (2019). Do peer effects influence the academic performance of rural students at private migrant schools in China? China Economic Review, 54, 418-433. https://doi.org/10.1016/j.chieco.2019.02.004.

15. Muñoz-Bullón, F., Sanchez-Bueno, M.J., Vos-Saz, A. (2017). The influence of sports participation on academic performance among students in higher education. Sport Management Review, 20(4), 365-378. https://doi.org/10.1016/j.smr.2016.10.006.

16. Pearce, A.R. (2017). Sustainable Urban Facilities Management. Reference Module in Earth Systems and Environmental Sciences-Encyclopedia of Sustainable Technologies, pp. 351-363. https://doi.org/10.1016/B978-0-12-409548-9.10183-6.

17. Reddy, K.S., Xie, E., \& Tang, Q. (2016). Higher education, high-impact research, and world university rankings: A case of India and comparison with China. Pacific Science Review B: Humanities and Social Sciences, 2(1), 1-21. https://doi.org/10.1016/j.psrb.2016.09.004.

18. Sidorenko, T., \& Gorbatova, T. (2015). Efficiency of Russian Education Through the Scale of World University Rankings. Procedia - Social and Behavioral Sciences, 166, 464-467. https://doi.org/10.1016/j.sbspro.2014.12.555.

19. Turner, L., Calvert, H.G., \& Chaloupka, F.J. (2018). Barriers to Shared Use of Indoor and Outdoor Facilities at US Elementary Schools. Journal of School Health, 88(5), 379-387. https://doi.org/10.1111/josh.12621.

20. Wu, J., Wei, X., Zhang, H., \& Zhou, X. (2019). Elite schools, magnet classes, and academic performances: Regression-discontinuity evidence from China. China Economic Review, 55, 143-167. https://doi.org/10.1016/j.chieco.2019.03.004. 